\title{
HACIA UN ENFOQUE LITERARIO FUINCIONAL EN EL ESTUDIO DE LOS TEXTOS ENCICLOPÉDICOS LATINOS TARDÍOS: PROBLEMAS Y PROPUESTAS ${ }^{1}$
}

\section{JULIETA CARDIGNI}

Universidad de Buenos Aires - CONICET

jcardigni@yahoo.es

Recibido: 09/06/20

Aceptado: $26 / 08 / 20$

En el presente trabajo nos proponemos estudiar los textos enciclopédicos latinos tardíos desde la perspectiva del Análisis del discurso basado en un marco teóricometodológico de carácter funcional. Nuestro objetivo principal es mostrar que, a partir de un enfoque funcional de género literario, que combine texto y contexto, es posible analizar de manera profunda obras que, desde estudios retórico-formales, presentan dificultades en su caracterización. Para acompañar el planteo del problema tomaremos como ejemplos dos obras de nuestro corpus: los Commentarii in Somnium Scipionis de Macrobio y De nuptiis Philologiae et Mercurii de Marciano Capela (ambos del s. V d. C.).

Análisis discursivo / Lingüística Sistémico Funcional / Enciclopedismo latino tardío / Macrobio / Marciano Capela

TOWARDS A LITERARY FUNCTIONAL APPROACH IN THE STUDY OF ENCYCLOPEDIC LATE LATIN TEXTS: PROBLEMS AND PROPOSALS

The present paper aims to study the late Latin encyclopedic texts from the perspective of Discourse Analysis based on Systemic-Functional Linguistics. Our principal objective is showing that, departing from a functional approach on literary genre, combining text and context, it is possible to analyze in a deep way works that, from formal perspectives, pose difficulties in their characterization. In order to accompany the statement of the 
problem, we will recur to two works belonging to our corpus: Macrobius' Commentarii in Somnium Scipionis de Macrobio ( $5^{\text {th }}$ century A.D.) and Martianus Capella's De nuptiis Philologiae et Mercurii de Marciano Capela (5 $5^{\text {th }}$ century A.D.).

Discourse analysis / Functional Systemic Linguistics / Late Latin encyclopedism / Macrobius / Martianus Capella

\section{Algunos problemas en el estudio literario de la literatura enciclopédica tardoantigua}

Toda investigación supone un problema que funciona como estímulo y punto de partida. Todo marco teórico, una forma novedosa y coherente de indagar sobre ese problema. La investigación aspira a lograr un acercamiento profundo al asunto y, en el mejor de los casos, a convertirse en el origen de nuevos interrogantes.

Nuestro punto de partida es el cuestionamiento a ciertas lecturas del corpus de textos enciclopédicos tardoantiguos instaladas por la tradición desde la Edad Media. Estas lecturas son rígidas y reduccionistas, y no dan cuenta de la naturaleza literaria de las obras ${ }^{2}$. En general, siguen vigentes porque en su mayoría cuentan con siglos de transmisión, a lo largo de los cuales se ha perdido cierta perspectiva del contexto y de las motivaciones que las generaron. En consecuencia, son lecturas que se han heredado y se reproducen casi por inercia, aunque las obras se vean forzadas por categorías genéricas a las que muchas veces no se adaptan. El resultado es una valoración crítica de estos textos como 'malos' ejemplares del género, o incluso como producciones bizarras que no responden a ningún tiempo y espacio, como si esto fuera posible. Cuando los resultados van en esa dirección, resulta evidente que es necesario modificar la mirada, ya que lo problemático no está en los textos, sino en el enfoque ${ }^{3}$.

El corpus sobre el que trabajamos está compuesto por textos enciclopédicodidácticos latinos tardíos (siglos IV-V-VI d. C.), de los cuales abordaremos en el presente trabajo los Commentarii in Somnium Scipionis de Macrobio y De nuptiis Mercurii et Philologiae de Marciano Capela ${ }^{4}$. En principio, lo que ubica a estos textos en una misma tradición es su tratamiento -parcial o total- de las disciplinas de la educación liberal, es decir, la enkýklos paideía, comprendida por la Gramática, la Dialéctica y la Retórica (para el trivium) y la Geometría, la Aritmética, la Astronomía y la Armonía (para el quadrivium $)^{5}$. Las obras de estos autores serán leídas, explicadas y comentadas por los hombres de la Edad Media, que absorberán de allí no solo las cuestiones relacionadas con las disciplinae cyclicae, sino también gran parte del bagaje filosófico de la tradición platónica, mayormente por la falta de los textos originales.

De más está decir que, por el solo hecho de abordar las disciplinas liberales, todas estas obras han sido consideradas didácticas; ya sea que se hable de manuales ${ }^{6}$, 
comentarios o enciclopedias, en todos los casos se les ha atribuido a estos textos un claro propósito instructivo. El problema es que el didactismo no se reduce a la exposición de determinados contenidos, o a la posibilidad de aprender algo de un texto (en este sentido, toda la literatura es didáctica), sino que es un fenómeno discursivo específico que supone determinadas estrategias textuales reconocibles por autor y lector. La etiqueta de "didáctico" tiene, en todo caso, un carácter bastante general, que apunta más bien a lo tipológico-formal. Se trata de un fenómeno transversal que, como único criterio para la asignación genérica es, por lo menos, insuficiente.

Pero lo cierto es que esta ligereza de clasificación genérica responde a una cuestión previa. Los textos enciclopédicos, por su naturaleza totalizadora y acumulativa, resultan heterogéneos, inespecíficos y muy permeables genéricamente. Por esto mismo existe cierta controversia a su alrededor, sobre la cuestión de si son o no literatura, o si son más bien literatura sobre la literatura, y, por lo tanto, textos de carácter menor o secundario $^{7}$. En general, la polémica es resuelta a favor de la opción menos literaria: son textos que transmiten saberes, fuente de información sobre la historia de la cultura, o de las ideas, y así son leídos -o más bien, utilizados- con un sentido "práctico". Esta apreciación tiene su origen en sus lectores medievales, "usuarios" de los saberes transmitidos en estos textos, que les permitían recuperar de manera ordenada elementos de la tradición clásica ${ }^{8}$. No obstante, es necesario reparar también en la textualidad de estas obras, en su esencia como hechos literarios, y leerlos en función de sus propias normas genéricas, sin por ello desestimar su aporte a la historia de la cultura, de cuya importancia nadie duda.

La crítica es consciente de este conflicto, y a menudo busca anularlo asumiendo la necesidad de la catalogación genérica de las obras, pero despejando esta cuestión al inicio de sus estudios con bastante ligereza, recurriendo a etiquetas como las de "manual", "comentario", "glosa", que resultan poco explicativas y en muchos casos solo tienen en cuenta elementos formales de los textos. De esta caracterización formal derivan también otros problemas como, por ejemplo, la imposibilidad de dar cuenta de las transgresiones genéricas de una obra, que da como resultado su calificación como "inepta", ya que no cumple con los patrones esperados. Otras veces, la combinación de tópicos, registros y voces dentro de una misma obra no es percibida desde una clasificación formal, y por ello la obra es juzgada como rara o excéntrica respecto de la etiqueta impuesta. Finalmente, suele ocurrir que, aludiendo nuevamente al carácter poco literario de los textos enciclopédicos, el tema no se considera tan relevante como su contenido referencial, y la cuestión de la caracterización genérica queda apenas planteada sin mayor reflexión.

El resultado de este proceso muchas veces culmina con la valoración de los textos enciclopédicos como simples operaciones de copiado y pegado (tanto Macrobio como Calcidio han sido objeto de esto $)^{9}$, o como monstruos bizarros que no responden a ninguna norma (como las obras de Marciano Capela y de Fulgencio) ${ }^{10}$, o bien, en los 
casos más inofensivos, simplemente se ven como una acumulación de información más o menos interesante pero sin organicidad discursiva (Servio y otros gramáticos suelen ser estudiados de esta manera) ${ }^{11}$. Literariedad, textualidad y género literario constituyen tres pilares interrelacionados de este problema que se plantea a la hora de abordar los textos enciclopédicos tardoantiguos. En los últimos años esta tendencia se ha ido revirtiendo y los autores enciclopédicos se han ido ganando un lugar en los estudios de carácter literario; sobre este movimiento articulamos nuestras reflexiones y nuestra propuesta ${ }^{12}$.

Por lo tanto, refinando la formulación previa, nuestro punto de partida es la dificultad existente en las caracterizaciones de la crítica en relación con el género literario de algunas obras del corpus enciclopédico latino tardío. Creemos que es necesario adoptar un enfoque que permita apreciar las obras en su esencia y en su relación con el contexto, y que rescate tanto su "textualidad", frente al fragmentarismo con el que a veces se los lee, como su "literariedad", en contraposición con la idea de literatura secundaria o menor. No es el objetivo imponerles nuevas etiquetas genéricas, sino permitirles expresar su mensaje profundo y su dinamismo literario. Y consideramos que la noción de género literario -que, en nuestro caso, adoptará un carácter funcionalista- resulta clave en este proceso.

\section{El enfoque funcionalista en el análisis discursivo de los textos latinos tardoantiguos}

Adoptamos el marco teórico de la Lingüística Sistémico-Funcional (LSF), retomado por la Escuela de Sydney sobre la propuesta bajtiniana, que provee de elementos concretos de análisis para abordar el estudio de obras de alta permeabilidad y baja especificidad genéricas ${ }^{13}$. Es la intención de este apartado ofrecer una presentación teórica breve de este marco metodológico, y permitirnos destacar algunos elementos relevantes para nuestro análisis ${ }^{14}$.

En primer lugar, la LSF considera la lengua como un sistema de opciones, y por lo tanto cada elección discursiva del hablante, en todos los niveles del discurso, adquiere significado en su contexto y en relación con las restantes opciones disponibles en el sistema. En consecuencia, el discurso es percibido no sólo como producto sino como proceso, y el análisis discursivo busca desandar el camino de construcción de sentido de la obra. Asimismo, la LSF adopta una concepción sociosemántica y no determinista de la lengua, en la cual texto y contexto se construyen bidireccionalmente. La lengua es, así, un sistema que realiza y manifiesta las estructuras semióticas que conforman una sociedad y una cultura determinada.

A su vez, dado que la LSF plantea una activación gradual de los rasgos asociados con determinados recursos discursivos, el análisis permite percibir y establecer diferencias sutiles dentro de los ejemplares de un género, y permite asignarles un 
significado en relación con las otras opciones que ofrece el sistema. Así, por ejemplo, en el nivel de los géneros literarios, no podemos pensar que la elección de la sátira menipea por parte de Marciano Capela en el caso de su obra De nuptiis haya sido inocente, sino que resulta significativa en el marco de los géneros disponibles didácticos y no- para Marciano al momento de escribir su obra. No optó, para sistematizar las Artes liberales, ni por el comentario, ni por el tratado, sino por la sátira menipea, y eso es un dato significativo a tener en cuenta antes de clasificar De nuptiis con liviandad como un texto didáctico. Nadie niega que haya en Marciano elementos de carácter didáctico, pero un análisis funcional puede ayudar a reevaluarlos y a ponderar su relevancia y función dentro del texto.

Asimismo, en esta teoría el lenguaje es funcional en tres sentidos distintos y estrechamente relacionados: en su interpretación de los textos, en su interpretación del sistema y en su interpretación de los elementos de las estructuras lingüísticas. En principio la teoría es funcional porque está diseñada para dar cuenta de cómo se usa la lengua, pero en un sentido más estricto, el concepto de función es interno a la lengua ${ }^{15}$, en tanto esta es un sistema de opciones que sirve para construir significados ${ }^{16}$. Así, y dado que el discurso se sitúa en la intersección entre el marco cognitivo social la gramática- y el sociocultural -los géneros discursivos-, el análisis parte del "textodiscurso" y específicamente de la cláusula, unidad mínima de análisis sobre la cual se proyectan las tres funciones del lenguaje (ideativa, interpersonal y textual). Esta posición supone una doble relación con los otros ámbitos mencionados: por un lado, con el análisis gramatical como punto de partida; y por otro, con el contexto sociocultural, es decir, con los géneros discursivos disponibles, puesto que a partir de la explicación de la variabilidad presente en el registro (a través del estudio de las categorías de campo, tenor y modo), por medio del análisis discursivo se logra una interpretación en términos de género, que trasciende al ámbito sociocultural ${ }^{17}$.

Por estas características, en principio, la LSF ofrece varias ventajas de análisis por sobre otras perspectivas formales o retóricas -más usualmente aplicadas sobre textos clásicos- al permitir el estudio y la caracterización de géneros de mayor inespecificidad y permeabilidad genérica, para los que las etiquetas formales resultan insuficientes. Esto ocurre en el caso de textos muy heterogéneos, como la mencionada sátira menipea, o el comentario. Hablar de "comentario" y enumerar simplemente sus rasgos formales nos deja en presencia de un conjunto de textos muy disímiles entre sí (como los de Macrobio, Calcidio, Servio, Porfirio, Favonio Eulogio) que solo tienen en común la exégesis sobre un texto precedente. La operación de comentar es muy amplia, y permeable a diferentes formas discursivas, y el resultado en cada caso puede ser muy diferente. Asimismo, intentar comprender la sátira menipea a partir del uso del prosimetrum -su rasgo formal característico y más conspicuo- no resulta ni explicativo ni tampoco preciso. El prosimetrum es apenas un sustrato formal del género, y no todas las obras que se construyen sobre este recurso son sátiras menipeas, ni todas las 
sátiras menipeas actualizan este recurso de la misma manera. No se trata entonces de desmerecer enfoques formales o retóricos, porque el funcionalismo no se opone a ellos, sino de complementarlos. Mientras que un análisis formal tiene un gran alcance descriptivo, un abordaje funcional tiene un mayor carácter explicativo, ya que pone esos rasgos en relación con su contexto y permite una construcción de sentido más completa.

La escuela de Sydney, marco específico en el que nos situamos dentro del funcionalismo, retoma la idea de género discursivo propuesta por Bajtín y le otorga mayor precisión y autonomía. Se propone una noción de género estratificada, que comprende el texto, su registro -es decir, la adecuación al contexto situacional- y las convenciones culturales -es decir, los géneros discursivos- como niveles de realización que se proyectan uno en el otro. Asimismo, la noción de género es teleológica, ya que el género responde a un propósito social, siempre ligado a su contexto ${ }^{18}$. Un género es, desde esta perspectiva, un proceso social orientado a determinados fines que presenta cierta estructura organizativa; asimismo, a la estratificación del contexto se suma la ideología, componente textual general que permite estudiar la distribución sociohistórica, mediada por variables sociales de clase, edad, sexo, origen étnico, de los géneros y registros ${ }^{19}$. Por medio de estas precisiones se busca distinguir la noción de registro de la LSF de la de género establecida por Bajtín, y hacerlas convivir armoniosamente en el modelo; así para MARTIN (1984, p. 155) "a genre is a staged, goal-oriented, purposeful activity in which speakers engage as members of our culture".

Entonces, si bien podemos encontrar una sistematización de las disciplinas del trivium y del quadrivium en la obra de Marciano, no por eso se transforma en una obra didáctica, si su propósito social no es instruir. Si es más bien desequilibrar o atacar por medio de la parodia lugares culturales comunes, este rasgo -sumado a otros interpretables en la misma dirección- apunta hacia el género de la sátira menipea, que es desestabilizador y crítico. Podemos, como los hombres medievales, leerla para saber (quizá) de qué se trataba la retórica en la educación romana tardoantigua, pero eso no significa que el propósito de la obra sea la configuración de un tratado de Retórica. De la misma manera, si en el Comentario de Macrobio, subclasificado como "filosófico" por la tradición, encontramos que las explicaciones filosóficas están en función de la construcción de un modelo ejemplar de romanitas, erigido a través de la ficcionalización de la figura de Escipión, entonces el propósito social no será explicar el texto de Cicerón, sino moldear una nueva identidad para el romano tardoantiguo. Quizá esto no necesariamente amerite una nueva clasificación genérica, pero sí una nueva mirada sobre la composición del texto.

Registro y género conforman, entonces, los contextos de los textos, pero el primero es la variedad del uso de la lengua determinada por la situación, mientras que el género es el contexto mediato, determinado por las convenciones culturales. Un texto, para ser tal, deberá ser consistente en registro y género, y cohesivo, respetando o 
transgrediendo las normas, pero nunca desconociéndolas. Tenemos, entonces, de manera esquemática, tres componentes en un texto, que cuentan con una dimensión paradigmática (las opciones disponibles) y una sintagmática (las opciones realizadas): el sistema gramatical, el dispositivo estratégico (registro), y la adscripción genérica (géneros). La relación entre estos niveles es de realización, y dado que la lengua y su semántica son un continuum, cualquier adscripción será una cuestión de grado. Si los recursos gramaticales de un texto activan una lectura estratégica orientada hacia la parodia, podremos inscribir ese texto en un registro paródico; $y$, a su vez, si este registro paródico predomina en una obra y se activa con más fuerza que otros registros -con los que convive-, entonces podremos adscribir la obra al género de la sátira menipea, como en el caso de Marciano, dado que el registro paródico es consistente con ese género. De la misma manera, si bien sabemos que la sátira menipea supone el uso del humor mezclado con lo serio, el grado de esta mezcla, así como su función, quedan circunscriptos al contexto de cada obra, y a la relación que este recurso establece con otros rasgos presentes. La Consolatio de Boecio y De nuptiis de Marciano son ambas sátiras menipeas, aunque podemos coincidir en que el humor se encuentra muy restringido en la primera, y más explotado en la segunda ${ }^{20}$. Así, la adscripción genérica no es solo una etiqueta formal, sino una clave esencial de lectura. Y, sobre todo, no es una etiqueta fija, sino una categoría dinámica y gradual.

Por último, la LSF cuenta con un concepto muy interesante para analizar el tipo de textos a los que nos enfrentamos: el de "metáfora contextual" 21 . Ligada en principio a la misma idea que la "metáfora gramatical", tal como es propuesta por Halliday, se trata de una tensión, pero en el estrato del contexto, un desplazamiento del sentido en el ámbito del género que se ve realizado en una o más de una variable del registro (campo, tenor, modo). De alguna manera el escritor "anuncia" que se trata de un género, y sus instrucciones de interpretación apuntan en dirección de un género preciso; sin embargo, su propósito social es otro, es decir que el texto en contexto recibe una interpretación diferente. Esta tensión se realiza en las variables del registro: puede darse en la función interpersonal, o en la modal o en la ideacional. Pero de una forma u otra es un acto indirecto, dado que, si bien hay una apropiación de un género en cuanto a algunas de sus características, su interpretación en el otro contexto otorga sentido al texto de manera completa. Este concepto nos permite otro nivel de análisis en los textos, y permite dar cuenta de sus transformaciones de manera dinámica. Por ejemplo, Macrobio escribe un texto que la tradición considera un comentario, que él mismo denomina "comentario"22, y le da la forma estereotípica del comentario; sin embargo, en su contexto de producción el texto funciona como una propuesta de identidad romana en época tardía, a través de la construcción de un héroe ejemplar (Escipión), y no como una explicación de Cicerón en clave platónica.

A fin de cuentas, desde esta perspectiva se sugiere que en la interpretación de los textos los significados no están dados, sino que se construyen a partir de la interacción 
social, por ejemplo, entre autor y lector. A su vez, tanto la producción de significación que constituye una visión del mundo, como las situaciones interactivas, suponen una dependencia cultural y contextual: los textos son el medio en que esa dependencia cultural se ve representada, y siempre están inscritos en una situación interaccional determinada, propia de una cultura determinada ${ }^{23}$.

Finalmente, acerca de la legitimidad de aplicar un corpus teórico moderno a textos de la Antigüedad, diremos con DEPEW-OBBINK (2000) que el objetivo de una teoría de los géneros es proveer al crítico de una estrategia para abordar los textos, y que el provecho de una u otra concepción de género dependerá de su capacidad para iluminar la obra estudiada. Esto de ninguna manera sugiere forzar la lectura, sino más bien interrogar a los textos desde un lugar diferente. Según el propio HaLLIDAY (2005), el único requisito para aplicar el análisis lingüístico a un texto literario es que la teoría que se aplica exista con anterioridad, sea válida y relevante para el propósito del análisis, y que la lengua en cuestión pueda ser descripta sincrónicamente en relación con el texto que se estudia. Estas condiciones se verifican en este caso, ya que contamos con descripciones de la norma, el uso y funcionamiento de la lengua latina en la Antigüedad Tardía -tanto de la propia Antigüedad Tardía, como de nuestra época sobre este período-, es relevante un estudio de género aplicado a textos clásicos que tenga en cuenta variables que hasta ahora se han abordado de forma marginal, $y$, finalmente, la LSF resulta una teoría coherente, sólida y que ha producido resultados visibles y prácticos en su aplicación ${ }^{24}$. El hecho de que los trabajos de la LSF hayan partido de la lengua inglesa, y sea esta en la que se ha desarrollado la mayoría de los análisis, no constituye una limitación para su aplicación. La teoría se pretende universal en su concepción del lenguaje, y es esperable que su aplicación sea válida para cualquier lengua. Aunque hoy en día es una lengua de corpus, el latín fue -y en un sentido amplio, aún es- una lengua comunicativa.

De igual forma, los últimos acercamientos a la lengua latina desde la Lingüística han adoptado un enfoque funcional, tal como se verifica en las obras de, entre otros, Baños Baños (2009), DeVine-Stephens (2006), PANHuIS (1982), PinKSTER (1995) y TORREGo y DE LA VILLA (2009). La tendencia a considerar el latín desde el punto de vista funcional es la dominante en nuestros días. Es verdad que la mayoría de las herramientas del funcionalismo están en este momento destinadas a la explicación de la lengua latina con fines didácticos, y no pensando en el análisis de textos, como estamos proponiendo. Pero estos trabajos nos proveen de la base necesaria para la adaptación del marco teórico al latín ${ }^{25}$.

\section{Dos casos para el análisis: Macrobio y Marciano Capela}

Entrando ahora en la reflexión sobre nuestro corpus, y aunque ya hemos adelantado varias cuestiones, debemos tener en cuenta antes que nada el contexto literario en que 
las obras se sitúan, especialmente en el marco de una teoría contextualista como la que estamos proponiendo ${ }^{26}$. En la Antigüedad Tardía, el panorama de los géneros discursivos, como tantos otros paradigmas en la época, se encuentra en transformación, y en este sentido no solo estos géneros más "permeables" manifiestan cambios, sino que también lo hacen otros más tradicionales y encasillables, como la épica. La experimentación y la metamorfosis son los imperativos de la época ${ }^{27}$, en el marco de una poética de transgresión y cambio, que está en consonancia con la reconfiguración y búsqueda de respuestas que afectaban a toda la cultura del período. En un mundo que estaba cambiando, y cuyo imaginario se volvía cada vez más heterogéneo y caótico, la búsqueda de nuevas formas de representación adoptó estrategias retóricas impensables en épocas pasadas. En consecuencia, se ensayaron experimentos literarios que atentaban contra el ideal normativo de la poética clásica ${ }^{28}$. En este contexto, el funcionalismo resulta particularmente provechoso para el análisis de textos, dado que géneros que quizá en épocas previas podían ser caracterizados sin mayor problema a partir de patrones formales, se encuentran en transformación y desafiando esas mismas normas heredadas, que resultan ya insuficientes para dar cuenta de su naturaleza ${ }^{29}$.

En primer lugar, entonces, tomemos el caso de los Commentarii macrobianos al Somnium Scipionis de Cicerón. Lo primero que notará el estudioso de los comentarios -ya sean clásicos, tardíos, o medievales- es la existencia de grandes diferencias entre textos que son etiquetados como tales únicamente porque hacen una exégesis explícita de un texto anterior, y porque comparten determinadas fórmulas y estructura en su entramado textual $^{30}$. Lo cierto es que si uno obvia la relación con el contexto, así como el propósito social de cada obra, los Comentarios de Servio, el Comentario de Calcidio y el de Macrobio pertenecen al mismo género, o "tipo". El gran problema sigue siendo que, con un conjunto de parámetros tan amplios, y de carácter formal, la etiqueta "comentario" termina siendo poco significativa para dar cuenta de rasgos más sutiles.

El análisis de los Commentarii de Macrobio desde una perspectiva funcional permite revisar varias cuestiones, e incluso proponer un nuevo "subgénero" o "subtipo" dentro del género comentario, que podemos denominar "narrativo-ficcional". En particular, es útil el ya mencionado concepto de "metáfora contextual", por medio del cual se puede profundizar el análisis de una obra detectando desplazamientos en la interpretación de sus rasgos. Tradicionalmente, el texto de Macrobio ha sido considerado un comentario filosófico (en oposición al escolar, del cual la obra de su contemporáneo Servio es el mejor ejemplo). El rasgo esencial para inscribirlo en esta categoría es la presencia de la discusión sobre temas filosóficos como estrategia central para desentrañar el sentido del texto comentado, de carácter filosófico a su vez. Esto, más la presencia de textos de la tradición platónica, y la explicación de algunos aspectos del quadrivium, le ganaron a Macrobio un lugar entre los comentaristas filosóficos, entre los historiadores de la Filosofía, e incluso entre los filósofos ${ }^{31}$. 
Lo que nos interesa destacar en los Commentarii, a partir del análisis funcional, es que su eje de lectura se encuentra desplazado, de la explicación del texto de Cicerón, que propone su crítica tradicional, o de la exposición de elementos filosóficos usando como excusa el texto fuente, o de la explicación del quadrivium, a la construcción de la figura de Escipión como héroe ejemplar, que, en su versión tardoantigua, se propone como un héroe lector ${ }^{32}$. Si bien Macrobio vuelve al lema citado cada vez que redondea un comentario, su interés es exponer los contenidos filosóficos, y aludir a la tradición platónica, sólo en tanto esto lo ayuda a caracterizar a la figura de Escipión. Así, las famosas digresiones numéricas del libro I, en relación con la profecía de Escipión abuelo, confluyen no en la tradición pitagórica que se rememora, sino en la caracterización de Escipión como poseedor de la edad perfecta para hacerse cargo de la República (In Somn. Sc. 1.2.4 = SS 2.2). De la misma manera, el excursus denominado Tratado de las virtudes (1.8) le sirve a Macrobio no únicamente para hacer una exposición plotiniana-porfiriana de las virtudes sino para erigir a Escipión como aquel que las reúne.

Para precisar aún más los rasgos de su héroe, los episodios de sueños "mal leídos" (el de Agamenón y el de Virgilio, referidos y analizados por Macrobio en 1.7.4-8) funcionan como contraejemplos de las prácticas de Escipión, buen lector de las palabras proféticas de su abuelo ${ }^{33}$. Y, como no podía faltar en tanto tópico de los manuales de la época, Aristóteles se yergue como modelo del "mal lector", porque se ha apartado de la tradición y de su maestro, y ha leído en discordancia con él (2.15.1$21)^{34}$. Escipión, como todo romano de la época sabía, había podido cumplir con su destino político; lo que Macrobio suma es la explicación de cómo, o por qué, lo ha logrado: ha sido un buen lector. Así, son las habilidades lectoras -no ya las bélicas, o las políticas- las que Escipión reúne como modelo ejemplar de una romanidad que, en época de Macrobio, es ya otra.

También desde lo metaliterario Macrobio refuerza esta propuesta: sus excursus sobre los sueños y sobre las ficciones (1.2.7), que le valieron tanta fama durante el Medioevo, constituyen propuestas exegéticas y claves de lectura para orientar al lector. Para clasificar las ficciones, Macrobio echa mano de varios criterios que combina, con el objetivo de llegar a la categoría de narratio fabulosa, en la que entra el episodio del sueño ciceroniano, forma literaria que está intentando caracterizar. Esta forma de ficción se caracteriza por desarrollar lo verdadero a través de lo falso, y en establecer su relación con la verdad de manera misteriosa, simbólica (ya que no es icónico-mimética, no "copia" la realidad) $)^{35}$. De esta manera, Macrobio rescata la ficción, redefiniéndola como un recurso útil y, en algunos casos, incluso más eficaz que el discurso verídico. También su obra presentará elementos claros de "ficcionalización", relacionados sobre todo con la composición del personaje principal, Escipión.

Esta clasificación novedosa de Macrobio nos muestra que la forma de leer y de interpretar ha cambiado, porque ha cambiado la forma de representar la realidad. La 
alegoría simbólica requiere de otras virtudes por parte de los lectores, son esas las que Macrobio buscar desarrollar, son esas las que su héroe Escipión condensa en su figura, y son esas las que los hombres tardoantiguos deben forjar para constituir una nueva romanitas $^{36}$.

Esto es coherente con el contexto de producción de la obra, en que las tradiciones literarias y filosóficas buscaban su inserción en la tradición, al mismo tiempo que la transformación de los valores de la romanidad para adaptarla a los nuevos tiempos. Una forma eficaz para esta reconfiguración desde el punto de vista literario es la ficcionalización, que Macrobio defiende de manera metaliteraria, y aplica a la hora de componer su obra. Aquí Macrobio se desplaza desde el tono filosófico al tono narrativo ficcional, construyendo un texto lleno de alusiones épicas para la configuración de su héroe y del viaje que es, finalmente, la interpretación del texto ciceroniano. Como un nuevo Eneas, pero buen lector, Escipión refunda Roma en el Tardoantiguo a partir de su interpretación correcta de las palabras de su abuelo, espejadas en la correcta interpretación que el propio Macrobio hace de Cicerón, y en la que los lectores debemos hacer del comentario. Este desplazamiento sobre modelos previos habilita la consideración de la obra macrobiana como una metáfora contextual, que al mismo tiempo que desplaza el propósito social de su comentario (de explicar a proponer un modelo de romanitas), se hace eco del desplazamiento identitario que experimentaban los hombres tardoantiguos.

En el caso de Marciano, el punto de partida es menos sutil: gran parte de la tradición lo ha considerado un autor bizarro, excéntrico e ininteligible. Como epítome de estas apreciaciones, podemos recordar la famosa declaración de LEWIS (1958): "for this universe, which has produced the bee orchid and the giraffe, has produced nothing stranger than Martianus Capella" que, más allá de que no implica en sí misma una connotación negativa, sí da cuenta del carácter entre llamativo y monstruoso de la obra $^{37}$. La imposibilidad de clasificación que se aprecia en las palabras de Lewis surge una y otra vez como problema a la hora de enfrentarse a la lectura de De nuptiis. Esta pretendida excentricidad hace que la obra se pierda en una dimensión desconocida, fuera de tiempo y espacio. La crítica suele aceptar esta dificultad como insoluble, y sigue adelante en la lectura e interpretación de otras cuestiones no puramente literarias, ya que ciertamente no escasean en Marciano Capela misterios de todo tipo ${ }^{38}$.

De nuptiis Philologiae et Mercurii cuenta con dos secciones. Los dos primeros libros narran la fábula alegórico-epitalámica sobre la búsqueda de esposa por parte de Mercurio, el compromiso con Filología y su ascenso hacia las sedes celestes para alcanzar la inmortalidad y casarse con el dios. En los siete libros restantes, cada una de las Artes liberales, encarnadas en las damas de honor que el novio regala a su prometida, discurren sobre sus disciplinas, ante la Asamblea de los dioses que, algo azorados por el rumbo que toma la ceremonia nupcial, y francamente aburridos por los discursos disciplinares, muestran su fastidio interrumpiendo. Todo esto enmarcado en 
un diálogo entre Marciano y su hijo, matizado por conversaciones metaliterarias con Sátira, el género literario, que recorren todo el texto. El contenido referencial de las Artes ha sido suficiente para que la obra se considere didáctica -ciertamente, es una sistematización relativamente ordenada y completa de los saberes de la Antigüedad, sobre todo ante la falta de fuentes directas- y en este panorama los dos primeros libros son considerados una introducción amena al contenido científico.

Sin embargo, hay varios elementos que no confluyen hacia esta interpretación. De manera general, las dos secciones de la obra no están separadas, sino que la trama ficcional permea todo el texto, y el argumento sigue su desarrollo al menos como marco de los discursos de las Artes. La fabula ${ }^{39}$ inicial no parece una excusa ni una elaborada captatio, sino que juega un papel constitutivo en la obra.

En particular, el elemento clave que nos interesa señalar en este punto es el de la parodia. Desde una perspectiva formal, como la que a menudo se aplica para leer a Marciano, la parodia es un recurso retórico, que puede funcionar como forma de entretenimiento o como distensión para presentar los contenidos científicos. Lo mismo ocurre cuando se analiza la trama ficcional. Sin embargo, desde la LSF, la parodia no es un recurso retórico, sino un registro. En este sentido, el análisis muestra que es el registro dominante en la obra, y que, por lo tanto, es necesario subvertir la lectura. Los rasgos de didactismo efectivamente están presentes, pero solo construidos como objeto de burla y crítica.

Por otro lado, parte de la crítica ha aceptado -sin resignar el carácter didácticoque De nuptiis es una sátira menipea. El elemento fundamental que toman para ello es la presencia del prosimetrum, alternancia de prosa y verso que caracteriza a la menipea. Así, han considerado que se trata de una "enciclopedia menipea". Nuevamente la apreciación de un rasgo formal oscurece una apreciación más profunda de la obra. El uso del prosimetrum es un rasgo que la menipea comparte con otros géneros, elemento necesario, pero no suficiente para la caracterización genérica. Por otro lado, la etiqueta de "enciclopedia menipea" resulta polémica, si asumimos que la menipea tiene una motivación disolvente, que en este caso se manifestaría como "antididactismo".

El análisis funcionalista conduce a interpretar la obra de Marciano como una sátira menipea en la cual la parodia constituye un rasgo central y fundante, que además se combina con la mezcla entre lo cómico y lo serio, y con un efecto crítico desestabilizador, que no busca atacar un sistema para poner otro en su lugar, sino simplemente "mover el piso" del lector, sin ofrecerle ninguna seguridad a cambio ${ }^{40}$. Un análisis funcionalista de la parodia como registro lleva a detectar niveles de uso de la parodia, así como sus objetos privilegiados, entre los cuales destaca el saber discursivo o, más bien, el discurso. En coherencia con ello, los pocos pasajes "serios" de la obra, en los que la parodia se retira, el protagonista es el silencio. Discurso y silencio se yerguen como los ejes de lectura de la obra, claves para su comprensión. Asimismo, al 
poner el análisis de la parodia en contexto con el panorama de las reflexiones tardoantiguas, observamos que el silencio, el discurso y sus problemas son centrales en la literatura de la época, al punto que se ha utilizado el término de "Poética del silencio" para caracterizar a la literatura tardoantigua ${ }^{41}$. En este contexto, la otrora bizarra obra didáctica de Marciano Capela adquiere coherencia y sentido, y dialoga con su contexto cultural. Pero solo dialoga si la asumimos como sátira menipea, ya que en ese carácter parodia, critica y reflexiona sobre la posibilidad del "discurso después del discurso", preocupación común a quienes hacen literatura en la Antigüedad Tardía. Esto es, sin duda, mucho más productivo que considerar De nuptiis una fallida obra didáctica, producto de un "non sanus homo".

En este marco, un análisis funcionalista devuelve a Marciano a unas coordenadas temporo-espaciales, desde las cuales dialoga con sus contemporáneos alrededor de ciertas preocupaciones comunes. Asimismo, inscribe a su obra, De nuptiis, en una tradición genérica, sobre la cual Marciano juega e innova, pero a la cual ciertamente reconoce. Deja así de ser el inefable monstruo que maravillaba a los medievales y horrorizaba a la Edad Moderna para ser una obra literaria coherente con su tradición genérica y su contemporaneidad.

\section{Lecturas y lectores}

Una lectura que recupere la esencia literaria de los textos, pero que al mismo tiempo los ponga en relación y en función de sus contextos, permite que asomen elementos que de otra manera pasan desapercibidos, o son malinterpretados. Esta lectura nos acerca al proceso de creación, a las decisiones involucradas, y a los caminos creativos que condujeron a forjar los textos. Integrando las obras a sus contextos, se muestran como procesos dinámicos y significativos, por un lado, y como productos de su época, por otro. A su vez, dialogan con su contexto contemporáneo, pero también con su tradición y con su posteridad. Es la lectura, punto de articulación entre estos aspectos, la encargada de develar-como pretendía el comentario- el sentido oculto de los textos, tarea para la que Macrobio preparaba a sus lectores. O quizá, como quería Marciano, la tarea del lector es construir el sentido de manera activa, separándolo del discurso y reduciendo este último casi al absurdo por medio del ridículo para recuperar lo que tiene de significativo y, a la vez, de inefable, despojándolo de sus multiplicaciones y de sus falacias.

Por último, este acercamiento permite proyectar los textos también a su contexto más distante, este nuestro desde el cual los leemos e interpretamos. Un contexto que también los construye y los modifica, y a través del cual siguen diciéndonos siempre palabras nuevas. 


\section{Bibliografía}

AthaNASSIADI, P. (2005). La lutte pour l'ortodoxie dans le platonisme tardif. De Numenius á Damascius, París.

BAKHOuCHE, B. (2011). Calcidius: Commentaire au Timée de Platon. Vol. I-II, París.

BAÑos BAÑos J. M. (coord.). (2009). Sintaxis del latín clásico. Madrid.

BRown, P. (1971). The world of Late Antiquity: from Marcus Aurelius to Muhammad (A. D. 150-750), Londres.

CAMERON, Alan (1977). Paganism and literature in late fourth century Rome. Christianisme et formes littéraires de l'Antiquité tardive en Occident, Entretiens sur l'Antiquité classique XXIII, Vandoeuvres.

CAmeron, Alan (2011). The Last Pagans of Rome. Oxford.

Cameron, Averil (1998). El mundo mediterráneo en la Antigüedad Tardía (395-600). Barcelona.

CARDIGNI, J. (2010). Aristóteles vs. Macrobio: buenos y malos exegetas en Commentarii in Somnium Scipionis 2. 15. Philologiae Flores, Homenaje a Amalia Nocito, 285-296.

CARDigni, J. (2013). El comentario como género tardoantiguo: Commentarii in Somnium Scipionis de Macrobio. Buenos Aires.

CARDIGNI, J. (2015). Reading Classical Myths in Late Antiquity: Macrobius' Proposal of Literary Identity in Commentarii in Somnium Scipionis. Classical Myths Revisited, Proceedings of the International Conference "Recycling Myths". Lisbon.

CARdignI, J. (2018). De nuptiis Philologiae et Mercurii o la farsa del discurso. Una lectura literaria de Marciano Capela. Buenos Aires.

CONTE, G. B. (1986). The Rhetoric of Imitation, Genre and Poetic Memory in Virgil and other Latin Poets (Cornell Studies in Classical Philology XLIV). Trans. from the Italian. Ed. Charles Segal. Ithaca and London.

COULTER, J. A. (1976). The Literary Microcosm: Theories of Interpretation of the Later Neoplatonists. Brill.

De Nonno, M. (1990). Le citazioni dei grammatica. G. Cavallo, P. Fedeli, \& A. Giardina (eds.), Lo spazio letterario di Roma antica (Vol. 3, pp. 597-646).

DEPEW, M. E OBBINK, D. (2000). Matrices of genre. Cambridge, MA y Londres.

DeVINE, A. M. \& STEPHENS, L. D. (2006). Latin Word Order. Nueva York.

EDWARDS, R. (1976). Fulgentius and the Collapse of Meaning. Helios, 3, 17-35.

EgGiNS, S. E MARTIN, J. R. (2003). El contexto como género: una perspectiva lingüísticofuncional. Revista Signos, 36(54), 185-205.

Elsner, J. E HeRnÁNDEZ LobATo, J. (2017). The Poetics of Late Latin Literature. Oxford. 
FlamanT, J. (1977). Macrobe et le néo-platonisme latin, à la fin du IVe siècle. Leiden.

FONTAINE, J. (1977). Unité et diversité du mélange des genres et des tons chez quelques écrivains latins du la fin du IV siècle: Ausone, Ambroise, Ammien. Entretiens sur l' antiquité classique, 23, 425- 482.

GERSH, ST. (1986). Middle Platonism and Neoplatonism: The Latin Tradition. Notre Dame, Indiana.

Goulet- CazÉ, M. O. (2000). Le commentaire, entre tradition et innovation. París.

Hadot, I. (1985). Arts Liberaux et Philosophie Dans Le Pensee Antique. París.

Halliday, M.A. K. (1989). Language, Context and Text: Aspects of Language in a SocialSemiotic Perspective. Oxford.

HallidAY, M.A.K \& HASAN, R. (1976). Cohesion in English. Londres.

HALLIDAY, M.A.K \& HASAN, R. (1980). Language, Context and Text: Aspects of Language in a Social-Semiotic Perspective. Oxford.

HALLIDAY, M. A. K. E MATHIESEN, CH. (2004). An introduction to Functional Grammar. Londres.

JAMES, E. (2008). The rise and function of the concept «Late Antiquity». Journal of Late Antiquity, 1(1).

LEMOINE, F. (1972). Martianus Capella: A literary re-evaluation. Munich.

LEWIS, C. S. (1958). The Allegory of Love: A Study in Medieval Tradition. Oxford.

MoretTI, P. F., Ricci, R. E TORRE, C. (eds.) (2015). Culture and Literature in Latin Late Antiquity. Continuities and Discontinuities. Turnhout.

NaVArRo Antolín, F. (2016). Marciano Capela. Nupcias de Filología y Mercurio. Vol. 1 Las bodas místicas. Madrid.

Marrou, H. I. (1948). Histoire de l'éducation dans l'Antiquité. París.

MARTIN, J. R. (1984). Language, Register and Genre. En F. Christie (ed.), Children writing: a reader (pp. 21-30). Geelong, Vic.

MARTIN, J. R. (1997). Analyzing Genre: Functional Parameters. En F. Christie \& J. R Martin (eds.), Genre and Institutions. Londres.

MARTIN, J. R. E ROSE, D. (2007). Genre relations: mapping culture. Londres.

MCGILL, S., E PuCCI, J. (eds.) (2016). Classics Renewed: Reception and Innovation in the Latin Poetry of Late Antiquity. Heidelberg.

MCGILL, S. \& WATTS, E.J. (2018). A Companion to Late Antique Literature. Londres.

MENÉNDEZ, S. M. (2006). ¿Qué es una gramática textual? Buenos Aires.

MORIS, J. E NAVARRO, F. (2007). Género y Registro en la Lingüística Sistémico Funcional. Un relevo crítico. I Coloquio Argentino del Grupo ECLAR "Texto y Género", La Plata, 3 y 4 de diciembre de 2007. 
Munzl, L. (2011). Tecnica e ruolo dell' exemplum nei grammatici latini. En L'insegnamento delle technai nelle culture antiche (pp. 125-49).

PAnHuIS, D. G. J. (1982). The Communicative Perspective in the Sentence. A Study of Latin Word Order. Amsterdam/Philadelphia.

PARKER, H. (1890). The Seven liberal Arts. En The English Historical Review, 5(19), 417-461.

Pernot, L. (2006). La Seconde Sophistique et l'Antiquité Tardive. Classica 19(1), 30-44.

PINKSTER, H. (1995). Sintaxis y semántica del latín, Trad. por E. Torrego y J. de la Villa, Madrid.

QuirogA, A. (2010) La tercera sofística en el marco teórico de la historiografía sobre la Antigüedad Tardía y el postmodernismo. Talia dixi, 5, 75-90.

RELIHAN, J. (1993). Ancient Menippean Satire. Baltimore.

RosenmeYer, T. G. (2006). Ancient literary Genres: A Mirage. En A. Laird (ed.), Ancient Literary Criticism, Oxford.

Rostagni, A. (1952). Storia della Letteratura Latina, Torino.

SÁNCHEZ, L. (2009) La gramática del exemplum en el discurso de la retórica. Análisis de algunos casos en Rhetorica ad Herennium. Actas de las V Jornadas Nacionales "La(s) retórica(s) en la Antigüedad y sus proyecciones", Rosario.

SÁNCHEZ, L. (2015). La formación del registro metalingüístico en latín tardorrepublicano (s. I a. C.). El testimonio de De lingua latina de Varrón. RAHL, 7(1), 69-82.

SHANZER, D. (1986). A Philosophical and Literary Commentary on Martianus Capella's De Nuptiis Philologiae et Mercurii book I. Berkeley.

STAHL, W. H. (1971). The quadrivium of Martianus Capella: Latin traditions in the mathematical sciences, 50 B.C.-A.D. 1250 / by W. H. Stahl; with a study of the allegory and the verbal disciplines by R. Johnson, with E. L. Burge, Nueva York.

ToRrego, E. \& De LA VILLA, J. (2009). Contenidos de la Sintaxis Latina. Evolución y métodos de análisis. En J. M. Baños (coord.), Sintaxis del Latín Clásico (pp. 25-54). Madrid.

Van Winden, J. C. M. (1959). Calcidius on Matter, His Doctrine and Sources: A Chapter in the History of Platonism. París.

WASzINK, J. H. (1962). Timaeus, a Calcidio translatus commentarioque instructus. LondresLeiden.

Westra, H. (1998). Martianus Prae/postmodernus? Dionsysius, 16, 115-122.

WILLIS. J. (1952). Martianus Capella and his early commentators. Londres.

ZETZEL, J. (2018). Critics, Compilers, and Commentators: An Introduction to Roman Philology, 200 BCE-800 CE. Oxford. 
Notas

${ }^{1}$ Agradezco a mi colega Julia Burghini, por su lectura atenta y crítica de este trabajo, y por sus valiosas sugerencias.

${ }^{2}$ En la sección 3 nos explayaremos sobre este punto.

${ }^{3}$ Que no se malentienda: se trata de textos con dificultades varias, empezando por la lengua, como ocurre en Marciano y Fulgencio, donde diversos problemas morfosintácticos y también semánticos dificultan la comprensión. En otros casos, se suman a las particularidades lingüísticas los problemas de transmisión, y la mezcla de tradiciones de que echan mano los autores para su tarea de compendio. Es decir que son textos que ciertamente presentan desafíos, verificables en otros niveles como el genérico-literario. Con más razón es necesario buscar, como analistas literarios, un acercamiento que nos permita comprender su complejidad, y no estancarnos en visiones que resultan poco reveladoras.

${ }^{4}$ El corpus trabajado incluye los Commentarii in Somnium Scipionis y Saturnalia de Macrobio, el Commentarius in Timaeum de Calcidio, la Expositio Virgilianae continentiae y las Mythologiae de Fulgencio el Mitógrafo, y De nuptiis Philologiae et Mercurii de Marciano Capela. Queda de alguna manera aquí también incluida la categoría tipológica de "commentarii" gramaticales, que si bien no son considerados estrictamente "enciclopédicos" por su forma, podrían sumarse al corpus si pensamos que abordan la Gramática y sus vericuetos, por lo cual, por ejemplo, podemos sumar también los Comentarios de Servio o de otros autores tardoantiguos. Pero es cierto que, en comparación con las otras obras que mencionamos, pueden detectarse diferencias, y de hecho ZETZEL (2018, p. 6) distingue así los textos a los que nos dedicamos aquí, separándolos de los comentarios continuos: "There is a fourth category, which might be described as "works of antiquarian erudition" (or more bluntly as "none of the above"; not as all-encompassing as the erudition described by Grafenhan) and which overlaps with the others: works such as Aulus Gellius' Noctes Atticae, Martianus Capella's Marriage of Mercury and Philology, Macrobius' Saturnalia, and a few others contain learned scholarly discussions which are themselves meant as works of literature rather than as handbooks, commentaries, grammars, or other guides to reading". De todas maneras, el problema sigue siendo que "enciclopedismo" como categoría es transversal, y no es una distinción de género en sí misma, cf. STAHL (1971). Textos pertenecientes a diferentes géneros y formas pueden participar en la construcción enciclopédica del conocimiento relativo a las Artes liberales.

${ }^{5}$ En rigor, estos términos fueron utilizados por primera vez por Boecio a comienzos del siglo VI d. C. Respecto del surgimiento de las Artes liberales como ciclo, seguimos a I. HADOT (1985), quien sostiene que son producto del Tardoantiguo y del pensamiento neoplatónico en particular, frente a otras posturas que prefieren considerarlo ya presente en la Antigüedad Grecolatina, como MARROU (1948).

${ }^{6}$ En tanto Artes Grammaticae, dedicados a la enseñanza de la lengua. 
${ }^{7}$ Como notan MCGILL y WATTS (2018, pp. 5-6), la restricción moderna del término "literatura" a obras creativas (poesía, drama, ficción) es ajena a la Antigüedad. "Literatura" cubre un amplio espectro de textos, orales y escritos, a través de los cuales los individuos en la Antigüedad Tardía representaban, organizaban y entendían el mundo que los rodeaba. La línea entre texto literario y no-literario/sub-literario no estaba definida: "the category 'literature' comprises only texts to which authors and textual communities assign value that separates them from the purely functional and the disposable. This includes school exercises, which, even when they were throwaway student efforts belonged to literate culture and were designed to train the young to attain some level of rhetorical skill. Those exercises can also be placed within the bounds of literature for the same reason that texts like technical treatises and laws can be: They defy attempts to classify them as nonliterary because they possess features, notably linguistic selfconsciousness, representational strategies, rhetorical characteristics, and intertextual ties to authoritative textual models, associated with the literary. (...) Paraliterary and metaliterary compositions -e.g. commentaries, epitomes, and handbooks, all of which are characteristic of late antiquity- are not separate from the literary, moreover, but are extensions of it".

${ }^{8}$ No obstante el uso que hayan hecho los hombres medievales de los textos enciclopédicos, no debemos dejarnos engañar pensando que siempre los asumían como textos didácticos. Al menos Eriúgena, en la presentación de Marciano que hace en su Annotationes, señala que este "fingió ser un filósofo" (finxerit philosophus esse), indicando que percibe la máscara paródica de De nuptiis, más allá de que haga un uso de la obra funcional a sus propios objetivos pedagógicos. "Uso" no es "lectura"; y quizá gracias a esta confusión es que han sobrevivido en el tiempo las forzosas etiquetas didácticas para nuestros textos.

9 Por ejemplo, durante mucho tiempo el principal interés en Calcidio era la determinación e identificación de sus fuentes, cf. VAN WINDEN (1959), WASZINK (1962), y en Macrobio la valoración como transmisor indirecto de textos latinos perdidos o fragmentarios. En los últimos años, esta perspectiva ha ido cambiando; un ejemplo es BAKHOUCHE (2011) en el caso de Calcidio; CARDIGNI (2013), FlamANT (1977), para el caso de Macrobio.

${ }^{10}$ Más adelante se ofrece detalle sobre Marciano; sobre Fulgencio cf. un resumen de este tema en EDWARDS (1976). Hay también en estos casos un movimiento hacia la lectura "literaria", en contraposición con las lecturas previas que hemos consignado.

${ }^{11}$ Cf. De NonNo (1990, pp. 603-604): "Il ruolo essenziale dei grammatici antichi nel recupero frammentario di tanta parte della letteratura latina è dunque, dal nostro punto di vista filologico e storico letterario, fuori discussione; e in questa prospettiva strumentale non si può certo dire che il valore della loro testimonianza non sia stato ripetutamente -anche se non sempre soddisfacentemente- considerato in studi particolari, dedicati alla tradizione indiretta non solo di testi noti unicamente in questa forma, ma anche, com' è naturale, di autori conservatici direttamente dai manoscritti”.

${ }^{12}$ Por citar solo un ejemplo de cómo la técnica de los enciclopedistas de copiado y pegado está siendo revisada y revalorada, cf. MuNZi (2011, p. 127). 
${ }^{13}$ Gran parte de los estudios de la LSF aborda la problemática del género de textos escolares, que esencialmente comparten muchas de las características que presentan las obras de nuestro corpus, al enmarcarse también en la literatura considerada didáctica.

14 Sobre la LSF, cf. entre otros EgGiNS Y MARTIN (2003); HALLLIDAY (1989); HaLLIDAY Y HASAN (1976); HALLLIDAY Y MATHIESEN (2004); MARTIN Y RosE (2007). Para una exposición crítica de registro y género como conceptos fundamentales de la LSF, cf. MORIS Y NAVARRO (2007), cf. también MENÉNDEZ (2006).

${ }^{15}$ Cf. Halliday \& Hasan (1980).

${ }^{16}$ Cf. HALLidAY (1989, p. 17): "In other words, function will be interpreted not just as the use of language but as a fundamental property of language itself, something that is basic to the evolution of the semantic system".

${ }^{17}$ Cf. HALLIDAY \& MATHIESEN (1994, p. 26): "The system network is a theory about language as a resource for making meaning. Each system in the network represents a choice: not a conscious decision made in real time but a set of possible alternatives, like statement / question or singular / plural or falling tone / rising tone. These may be semantic, lexico-grammatical or phonological".

${ }^{18}$ Para HALLIDAY Y HASAN (1980, p. 39) y los otros autores que se sitúan en una postura más conservadora dentro de la Lingüística Sistémico Funcional, el registro es la variable funcional por excelencia, ya que la idea de contexto cultural -es decir, el género- no ha sido todavía incorporada de manera clara y sistémica, sino que se basan más en la noción de registro para dar cuenta de combinatorias más o menos estables de significados y de recursos léxicogramaticales y grafo-fonológicos que los realizan, asociadas a combinatorias más o menos estables de elementos contextuales. Es esta noción central de registro la que ha provocado desacuerdos dentro de la teoría, por su extensión original que de alguna manera subsume la de género.

${ }^{19}$ Cf. MARTIN (1984).

${ }^{20}$ Respecto de la sátira menipea antigua como género y su tradición, cf. RELIHAN (1993).

${ }^{21}$ Cf. MARTIN E ROSE (2007).

${ }^{22}$ Al comienzo del libro segundo (In. Somn. Sc. 2.1.1), Macrobio se refiere a la sección previa (In Somn. Sc. 2.1.1): Superiore commentario, Eustathi luce mihi dilectior fili usque ad stelliferae sphaerae cursum et subiectarum septem sermo processerat. ("En el libro anterior del comentario, Eustacio, hijo más querido para mí que la luz, el discurso había avanzado hasta el movimiento de la esfera estrellada y las siete inferiores.”) (La negrita es mía.)

${ }^{23}$ Cf. MARTiN (1997, p. 31).

${ }^{24}$ MENÉNDEZ (2006). Quizá lo que podemos señalar como crítica es el hecho de que coloca en un lugar secundario el papel del sujeto enunciador, si bien dentro de los postulados teóricos nada impide su inclusión en el análisis del texto, cf. MORIS-NAVARRO (2007). De hecho, para MENÉNDEZ (2006) el discurso es justamente el sujeto que lo produce más el texto producido. 
${ }^{25}$ Dado que una exposición de las adaptaciones del marco teórico al latín excedería los límites del presente trabajo, remito a CARDIGNI (2013); SÁNCHEZ (2009, 2015).

${ }^{26}$ Sobre la Antigüedad Tardía como categoría historiográfica, cf. ATHANASSIADI (2005); BROWN (1971); CAMERon, Al. (2011); CAMERON, Av. (1998); JAMES (2008); MCGILl \& PuCCI (2016); MORETTI, RICCI \& TORRE (2015), entre otros. Sobre una "Poética Tardoantigua", cf. ElSNER \& HERNÁNDEZ LOBATO (2017). Sobre la datación de Macrobio y Marciano Capela cf. entre otros Cameron, Al. (2011); Relihan, (1993); Shanzer, (1986). A los fines del presente artículo, consideramos que Macrobio vivió y escribió durante la primera mitad del siglo $\mathrm{V}$ d. C., y Marciano en la segunda mitad del mismo siglo.

${ }^{27}$ CAMERON, A. (1977); ElSNer E HeRnÁNDEZ LobATo (2017); FontAine (1977). Incluso se ha propuesto el término "Tercera sofística” para referirse a esta amalgama, cf. QUIROGA (2010), PERNOT (2006).

${ }^{28}$ Sobre este tema, cf. ELSNER \& HERNÁNDEZ LOBATO (2017).

${ }^{29}$ Es una polémica de por sí la discusión sobre la existencia o no de los géneros literarios en la Antigüedad, cf. ROSENMEYER (2006), es decir, si lidiamos con "géneros" o con "modelos". Adscribimos a la postura intermedia de CONTE (1986) quien propone el concepto de "género ejemplar", que combina los dos anteriores.

${ }^{30}$ Al respecto, cf. GOULET E CAZÉ (2000).

31 GERSH (1986) lo incluye entre los neoplatónicos latinos.

32 Cf. CARDigni (2015).

33 Tanto Agamenón como Virgilio fallan en interpretar sus sueños y, basados en el error, toman acciones -Agamenón, en la batalla; Eneas, en su viaje- que conducen a resultados inmediatos negativos.

${ }^{34}$ Macrobio explica el movimiento del alma dentro de la tradición platónica, y hace aparecer a Aristóteles como un "mal lector", dado que sobre la declaración de que "el alma se mueve a sí misma”, se empeña en ver dos elementos - un agente y un receptor- y en contradecir a Platón. Macrobio desarticula esta oposición con una explicación gramatical relacionada con la naturaleza de la voz media, en la cual el agente y el receptor son el mismo elemento, y acusa a Aristóteles de actuar "de mala fe" en su lectura, dado que no parece posible que al Estagirita se le hayan escapado estas cuestiones lingüísticas; cf. CARDIGNI (2010).

${ }^{35}$ Sobre la representación y su relación con la verdad en este contexto, cf. COULTER (1976).

${ }^{36}$ Esta es una preocupación que se percibe también, por ejemplo, en la obra de Fulgencio (si bien bajo el manto del registro paródico). Fulgencio diseña un método de interpretación que incluya el desplazamiento alegórico, pero que al mismo tiempo puede anclarlo para que el sentido no se desdibuje, por medio de la etimología. Al respecto, cf. EDWARDS (1976).

${ }^{37}$ Hay muchas otras valoraciones que ilustran esta cuestión: PARKER (1890, p. 444), opina que: "Martianus Capella's peculiarities are idiosyncratic and not the characteristic of any known age". Para WILLIS (1952), que retoma una frase del editor de Marciano que lo precedió (Eyssenhardt), 
estaríamos frente a un "non sanus homo", dada la forma en que trabaja con sus fuentes. NAVARRO ANTOLÍN (2016, pp. XXVI-XXVII), el traductor de su obra completa al español, señala: "Marciano Capela, a causa de la intencionada complejidad laberíntica de su estilo 'manierista', ha gozado casi siempre de mala fama como autor oscuro y hermético". Finalmente, RoSTAGNI (1952, p. 699) califica a De nuptiis como "bizarra sotto tutti gli aspetti". El planteo de este problema es también el punto de partida de LEMOINE (1972) en su propuesta de revalorizar la obra de Marciano desde una perspectiva literaria, que tomamos como antecedente de nuestro análisis, si bien a partir de enfoques metodológicos diferentes. Al respecto cf. también CARDIGNI (2018).

38 Son excepciones los trabajos de SHANZER (1986), RELIHAN (1993), y el ya mencionado de LEMOINE (1972). El trabajo de WESTRA (1998) muestra claramente la contradicción de que la crítica es presa al abordar a Marciano: de alguna manera el autor asume que se trata de una sátira menipea, pero no resigna su contenido pedagógico.

${ }^{39}$ Así llama Marciano al relato en dos ocasiones: en 1.3 "fabella”, y en 9.997 "anilem fabulam".

${ }^{40}$ Sobre la sátira menipea antigua, cf. RELIHAN (1993).

${ }^{41}$ Cf. ElsNer E HernándeZ Lobato (2017). 